\title{
Increase in postimplantation development of cultured mouse embryos by amino acids and induction of fetal retardation and exencephaly by ammonium ions
}

\author{
M. Lane and D. K. Gardner* \\ Institute of Reproduction and Development, Monash University, Monash Medical Centre, 246 Clayton \\ Road, Clayton, Victoria 3168, Australia
}

\begin{abstract}
The effects of amino acids and ammonium on the postimplantation development of cultured preimplantation mouse zygotes were assessed. Development after transfer revealed that the mouse embryo undergoes a switch in nitrogen requirements during the preimplantation period. Although Eagle's nonessential amino acids and glutamine supported the highest implantation and fetal development rates per embryo transferred when zygotes were cultured for $48 \mathrm{~h}$, by $93 \mathrm{~h}$ of culture the highest implantation rate was observed when all 20 amino acids were in the culture medium. Furthermore, fetal development per implantation at 69 and $93 \mathrm{~h}$ of culture was increased only in the presence of essential amino acids without glutamine. The beneficial effects of amino acids on postimplantation development when embryos were cultured for 4 days required that the medium be renewed after $48 \mathrm{~h}$ (at the 6-8-cell stage) to alleviate the build-up of ammonium. Ammonium was shown to induce fetal retardation and exencephaly in a time- and concentration-dependent manner. Renewal of amino-acid-free culture medium reduced fetal mass, providing indirect evidence for the production of an embryo-derived growth factor capable of stimulating postimplantation development. These data demonstrate that inclusion of amino acids in the culture medium for preimplantation embryos significantly increases postimplantation development, the preimplantation mouse embryo changes its nitrogen requirement as development proceeds, nonessential amino acids increase the implantation rate while the essential amino acids enhance fetal development, and ammonium in the medium retards fetal development and induces the neural tube defect exencephaly.
\end{abstract}

\section{Introduction}

The development of mammalian preimplantation embryos in vitro is associated with reduced cleavage rates (Bowman and McLaren, 1970a; Harlow and Quinn, 1982), species-specific blocks in development (Goddard and Pratt, 1983; Bavister, 1987), and subsequent reduction of viability (Bowman and McLaren, 1970b; Lane and Gardner, 1992). Conventionally, mammalian embryos are cultured in simple salt solutions with added carbohydrate energy substrates but no amino acids. However, fluid of the female reproductive tract is characterized by high concentrations of amino acids in vivo (Fahning et al., 1967; Miller and Schultz, 1987). Furthermore, the oocyte and embryo have a significant endogenous amino acid pool (Schultz et al., 1981), suggesting that amino acids have a physiological function.

Recently, it has been shown that supplementing embryo culture medium with specific amino acids reduces cultureinduced blocks to development (Chatot et al., 1989; Bavister and McKiernan, 1993; Gardner et al., 1994) and increases

*Correspondence.

Received 14 March 1994 cleavage rates (Gardner and Lane, 1993; Gardner et al., 1994). The observed increase in cleavage of mouse embryos in culture was due to Eagle's nonessential amino acids and glutamine (Eagle, 1959). In contrast, essential amino acids without glutamine reduced the blastocyst cell numbers after culture from the zygote (Gardner and Lane, 1993). The beneficial effects of amino acids are diminished by the generation of ammonium from both embryo metabolism and the spontaneous breakdown of amino acids in the medium at $37^{\circ} \mathrm{C}$ (Gardner and Lane, 1993). Optimal development of embryos in culture in the presence of amino acids therefore requires that the medium is renewed every $48 \mathrm{~h}$ to alleviate ammonium toxicity.

Although it has been shown that amino acids stimulate mouse embryo cleavage and development to the blastocyst stage, little is known about their effects on embryo viability or whether the build-up of ammonium impairs postimplantation development. The aim of this study was, therefore, to determine the role of specific groups of amino acids, medium renewal and ammonium on mouse embryo viability on successive days of development. A part of this study has been reported previously as an abstract (Lane and Gardner, 1994). 


\section{Materials and Methods}

\section{Media}

Modified mouse tubal fluid medium (mMTF; Gardner and Lane, 1993) was used as the basal medium for embryo culture

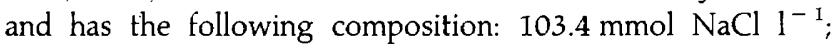
$4.78 \mathrm{mmol} \mathrm{KCl} \mathrm{l}{ }^{-1} ; 1.19 \mathrm{mmol} \mathrm{KH} \mathrm{PO}_{4} \mathrm{l}^{-1} ; 1.71 \mathrm{mmol}$ $\mathrm{CaCl}_{2} \cdot 2 \mathrm{H}_{2} \mathrm{O} \mathrm{l}^{-1} ; 1.19 \mathrm{mmol} \mathrm{MgSO} 4 \cdot 7 \mathrm{H}_{2} \mathrm{O}^{-1} ; 25 \mathrm{mmol}$ $\mathrm{NaHCO}_{3} \mathrm{l}^{-\mathrm{I}} ; 4.79 \mathrm{mmol}$ sodium lactate $\mathrm{l}^{-1} ; 0.37 \mathrm{mmol}$ sodium pyruvate $\mathrm{l}^{-1} ; 3.40 \mathrm{mmol}$ glucose $\mathrm{l}^{-1} ; 100 \mathrm{U}$ penicillin $\mathrm{ml}^{-1} ; 50 \mu \mathrm{g}$ streptomycin $\mathrm{ml}^{-1}$ and $0.01 \mathrm{~g}$ phenol red $\mathrm{l}^{-1}$. When mMTF was supplemented with either Eagle's nonessential amino acids and glutamine or essential amino acids without glutamine (Eagle, 1959), the $\mathrm{NaCl}$ concentration was reduced by $5 \mathrm{mmol}^{-1}$, or by $10 \mathrm{mmol} \mathrm{l}^{-1}$ when all amino acids were added to maintain the osmolarity at 260270 mosmol. Embryos were collected and manipulated in a Hepes-buffered modification of mMTF supplemented with nonessential amino acids and glutamine (H-mMTF), in which $20 \mathrm{mmol} \mathrm{NaHCO}_{3} 1^{-1}$ was replaced by $20 \mathrm{mmol} \mathrm{Hepes} \mathrm{l}^{-1}$ adjusted to $\mathrm{pH} 7.4$.

All salts and glucose were of analar grade (BDH, Poole) and sodium pyruvate, sodium lactate, amino acids and ammonium chloride were of cell culture grade (Sigma Chemical Co., St Louis, MO). Antibiotics were purchased from CSL (Parkville, Victoria). Hepes was obtained from Calbiochem (Alexandra, NSW) and BSA (Miles Pentex Crystalline) from Bayer Diagnostics (Kankakee, IL).

\section{Embryo collection}

Embryos were obtained from $(\mathrm{C} 57 \mathrm{BL} / 6 \times \mathrm{CBA} / \mathrm{Ca}) \mathrm{F}_{\mathrm{I}}$ hybrid females. Virgin females 4-6 weeks old were superovulated with an i.p. injection of 5 iu pregnant mares' serum gonadotrophin (PMSG; Folligon: Intervet, Lyppard, Victoria) at 16:00 h followed $48 \mathrm{~h}$ later by an injection of $5 \mathrm{iu} \mathrm{hCG}$ (Chorulon: Intervet). Females were mated with males of the same strain. Zygotes were collected in H-mMTF $21 \mathrm{~h}$ after hCG injection. Cumulus masses were dispersed by incubation with $1 \mathrm{mg}$ hyaluronidase $\mathrm{ml}^{-1}$ for less than $1 \mathrm{~min}$. Denuded zygotes were washed three times in H-mMTF and once in the appropriate culture medium before they were placed in culture. In each experiment, embryos from 8-10 females were pooled and randomly allocated to each treatment group.

\section{Culture conditions}

All embryos were cultured in groups of 10 in $20 \mu 1$ drops of culture medium (Lane and Gardner, 1992) under a layer of lightweight paraffin oil (Labchem, Ajax Chemicals, Auburn, NSW) in $35 \mathrm{~mm}$ Primaria Petri dishes (Falcon, Becton Dickinson, Victoria). All culture dishes were prepared on the morning of the culture and equilibrated for a maximum of $5 \mathrm{~h}$ before culture. Embryos were incubated at $37^{\circ} \mathrm{C}$ under $5 \% \mathrm{CO}_{2}$ in air.

\section{Embryo morphology}

Embryo morphology was assessed by phase contrast microscopy $(\times 200)$. Morphology was determined before transfer at 48,69 or $93 \mathrm{~h}$ of culture. Embryos classified as morulae included those with a blastocoel of less than two-thirds of the total volume; blastocysts included both expanded blastocysts where the blastocoel was greater than two-thirds of the total volume and fully expanded blastocysts that had begun to herniate through the zona pellucida.

\section{Determination of embryo viability}

Embryo viability was assessed by uterine transfer to pseudopregnant recipients. Recipient females were obtained by placing 8-12-week-old females of the same strain with vasectomized males. The day when a vaginal plug was detected was designated day 1 of pseudopregnancy. Each treatment was assigned to each uterine horn by random numbers and six embryos were transferred to a uterine horn. On day 15 of pregnancy, implantation sites, fetal development, fetal mass and the normality of fetuses were assessed.

\section{Assessment of fetal growth}

Fetal growth was assessed by the scoring system developed by Wahlsten and Wainwright (1977). A time scale of normal development for the strain of mice used in this study was initially established. Embryos at the blastocyst stage that had developed in vivo were flushed from the uteri of superovulated females using H-mMTF $93 \mathrm{~h}$ after hCG injection and were transferred to pseudopregnant recipients on day 4 . On days 13 , 14 and 15 of pregnancy, resultant fetuses were isolated and inspected. The morphological time scale was based on the development of the external features: skin, limbs, eye and ear. The normal range of development of each control fetus of gestational ages 13,14 and 15 days was assessed to establish normal developmental stages for each fetal age. Crown to rump length and fetal mass of the control fetuses were also assessed.

Each experimental fetus was assigned a morphological age for each feature based on the development of in vivo-derived fetuses. The score from the four features was averaged to give a morphological age accurate to 0.1 of a day. Crown-rump lengths were also compared as a second method to age the fetuses based on morphology (Wahlsten and Wainwright, 1977).

\section{Experimental design}

Effect of amino acids and medium renewal on embryo viability. Zygotes were cultured in one of four media: mMTF (control); mMTF supplemented with 20 Eagle's amino acids; mMTF supplemented with Eagle's nonessential amino acids and glutamine; or mMTF supplemented with Eagle's essential amino acids without glutamine.

In Expt 1 , embryos were cultured for $48 \mathrm{~h}$ to the 6-8-cell stage and were transferred to pseudopregnant recipients on day 3 of pseudopregnancy. In Expt 2, zygotes were cultured for $69 \mathrm{~h}$ to the morulae stage before transfer to day 3 pseudopregnant recipients. In Expt 3, zygotes were cultured for $93 \mathrm{~h}$ to the blastocyst stage. Half of the embryos in Expt 3 were transferred to fresh medium after $48 \mathrm{~h}$ of culture to alleviate the build-up of ammonium. The resultant blastocysts 
Table 1. Effect of amino acids on the viability of mouse zygotes cultured for $48 \mathrm{~h}$ to the $6-8$ cell stage

\begin{tabular}{|c|c|c|c|c|c|}
\hline Treatment & $\begin{array}{c}\text { Percentage of } \\
\text { implantation sites }\end{array}$ & $\begin{array}{c}\text { Percentage of fetuses } \\
\text { per transfer }{ }^{a}\end{array}$ & $\begin{array}{l}\text { Percentage of fetuses } \\
\text { per implantation site }\end{array}$ & $\begin{array}{c}\text { Fetal mass } \\
\text { (mean } \pm \text { SEM) } \\
(\mathrm{g})\end{array}$ & $\begin{array}{l}\text { Ammonium } \\
\text { concentration } \\
\text { after } 48 \mathrm{~h}^{\mathrm{b}} \\
\left(\mu \mathrm{mol} \mathrm{l} \mathrm{l}^{-\mathrm{l}}\right)\end{array}$ \\
\hline mMTF (control) & $33(22)$ & $21(12)$ & 55 & $0.1965 \pm 0.013$ & 0 \\
\hline $\mathrm{mMTF}+20$ aa & $39(26)$ & $17(\mathrm{I} 1)$ & 43 & $0.1896 \pm 0.012$ & 239 \\
\hline mMTF + nonessential aa + gln & $58(38)^{* *}$ & $32(21)^{*}$ & 55 & $0.1950 \pm 0.005$ & 112 \\
\hline mMTF + essential aa - gln & $32(21)$ & $23(15)$ & 71 & $0.1811 \pm 0.008^{*}$ & 82 \\
\hline
\end{tabular}

$n=66$ Embryos transferred per treatment.

${ }^{a}$ Numbers are indicated in parentheses.

'Gardner and Lane (1993)

*Significantly different from control value; $P<0.05$; ** significantly different from control value; $P<0.01$.

aa: amino acids; gIn: glutamine; mMTF: modified mouse tubal fluid medium.

were transferred to day 4 pseudopregnant recipients. All transfers were performed within $3 \mathrm{~h}$ of the designated end point of each culture. Embryos of the same morphology were selected for transfer from each medium, thereby negating any bias induced by different stages. On day 15 of pregnancy, implantation sites, fetal development, fetal mass and gross fetal normality were assessed.

Effect of the duration of exposure to ammonium in culture medium on subsequent embryo viability. Zygotes were cultured in either mMTF or mMTF supplemented with $300 \mu \mathrm{mol}$ ammonium $\mathrm{I}^{-1}$, the concentration present in medium supplemented with amino acids after incubation for $72 \mathrm{~h}$ (Gardner and Lane, 1993). Embryos were transferred to pseudopregnant recipients after 48,69 or $93 \mathrm{~h}$ of culture. On day 15 of pregnancy, implantation sites, fetal development, fetal mass and fetal normality were assessed.

Effect of ammonium concentration in the culture medium on embryo viability. Zygotes were cultured in MMTF alone (control) or in mMTF supplemented with the following concentrations of ammonium in the absence of amino acids: mMTF

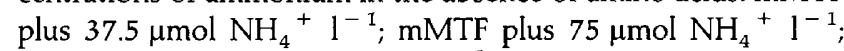
mMTF plus $150 \mu \mathrm{mol} \mathrm{NH}_{4}{ }^{+} 1^{-\mathrm{I}}$ or mMTF plus $300 \mu \mathrm{mol}$ $\mathrm{NH}_{4}{ }^{+} \mathrm{I}^{-1}$. Embryos were cultured for $93 \mathrm{~h}$ and transferred to the uteri of day 4 pseudopregnant recipients. Implantation sites, fetal development, fetal mass and resultant fetuses were assessed for morphological age on day 15 of pregnancy.

\section{Statistical analyses}

The data were analysed using a linear-logistic regression in which the error distribution was assumed to be binomial. The day of transfer was fitted as a factor to remove day to day variations. The null hypothesis of no-treatment effect against a treatment effect was tested with the log-likelihood ratio statistic (LRS). The LRS is approximately chi-square distributed. If zeros present in the data caused numerical problems, then 0.5 was added to sufficient cells to achieve numerical stability but without changing the inferences. The GLIM statistical package was used for the statistical analysis (Baker, 1988).

\section{Results}

\section{Effect of amino acids and medium renewal on embryo viability}

Culture for $48 \mathrm{~h}$ in media supplemented with Eagle's nonessential amino acids and glutamine significantly increased both the number of implantation sites $(P<0.01)$ and fetal development $(P<0.05)$ compared with culture in mMTF (control) (Table 1). Neither adding all Eagle's 20 amino acids nor essential amino acids without glutamine had an effect on the number of implantation sites or fetuses compared with the control medium. The mass of the fetuses resulting from culture with essential amino acids without glutamine was significantly lower than those in the control medium $(P<0.05)$. Fetuses from all treatment groups were morphologically normal.

A similar pattern of embryo viability was observed when embryos were cultured for $69 \mathrm{~h}$ (morulae stage) before transfer (Table 2), the nonessential amino acids plus glutamine significantly increasing the number of implantation sites compared with the control medium $(P<0.01)$. Culture in the presence of all amino acid treatments significantly increased the number of fetuses per transfer compared with culture in mMTF alone $(P<0.05)$. However, only essential amino acids without glutamine significantly increased the percentage of implantation sites resulting in fetuses compared with the control medium $(P<0.01)$. In contrast to embryos transferred to recipients after $48 \mathrm{~h}$, medium containing essential amino acids without glutamine significantly increased fetal mass compared with the control medium $(P<0.01)$. Culture to the morulae stage in all amino acid treatments resulted in the development of exencephaly (Table 2). An example of both a normal fetus and a fetus with exencephaly is shown (Fig. 1).

When embryos were cultured to the blastocyst stage in mMTF alone and transferred to fresh medium after $48 \mathrm{~h}$ (Table 3), the number of implantation sites was not significantly different from when embryos were cultured in the same medium throughout $(P<0.1)$; however, the resultant fetuses were significantly lighter than those cultured in the same drop of medium $(P<0.01)$. In contrast, embryos cultured in medium supplemented with all 20 amino acids that was renewed after $48 \mathrm{~h}$ to alleviate the build-up of ammonium exhibited a significant increase in both the number of implantation sites 
Table 2. Effect of amino acids on the viability of mouse zygotes cultured for $69 \mathrm{~h}$ to the morula stage

\begin{tabular}{lccccrr}
\hline Treatment & $\begin{array}{c}\text { Percentage of } \\
\text { implantation sites }\end{array}$ & $\begin{array}{c}\text { Percentage of } \\
\text { fetuses per } \\
\text { transfer }\end{array}$ & $\begin{array}{c}\text { Percentage of } \\
\text { fetuses per } \\
\text { implantation site }\end{array}$ & $\begin{array}{c}\text { Fetal mass } \\
(\text { mean } \pm \text { seM) } \\
(\mathrm{g})\end{array}$ & $\begin{array}{c}\text { Exencephalic } \\
\text { fetuses } \\
(\%)\end{array}$ & $\begin{array}{c}\text { Ammonium } \\
\text { concentration } \\
\text { after } 72 \mathrm{~h}^{\mathrm{b}} \\
\left(\mu \mathrm{mol} \mathrm{l}^{-1}\right)\end{array}$ \\
\hline mMTF (control) & $39(26)$ & $21(14)$ & 52 & $0.2094 \pm 0.017$ & $0(0)$ & 0 \\
mMTF + 20 aa & $52(34)$ & $36(24)^{*}$ & 68 & $0.2182 \pm 0.011$ & $20(5)$ & 414 \\
mMTF + nonessential aa + gln & $70(46)^{* *}$ & $36(24)^{*}$ & 52 & $0.2136 \pm 0.010$ & $4(1)$ & 265 \\
mMTF + essential aa - gln & $42(28)$ & $36(24)^{*}$ & $86^{* *}$ & $0.2298 \pm 0.015^{* *}$ & $4(1)$ & 168 \\
\hline
\end{tabular}

$n=66$ Embryos transferred per treatment.

${ }^{a}$ Numbers are indicated in parentheses.

${ }^{\mathrm{b}}$ Gardner and Lane (1993).

*Significantly different from control value; $P<0.05 ;{ }^{* *}$ significantly different from control value; $P<0.01$.

aa: amino acids; gln: glutamine; mMTF: modified mouse tubal fluid medium.

(a)

(b)

Fig. 1. (a) Morphologically normal mouse fetus on day 15 of pregnancy resulting from the transfer of a blastocyst derived in vivo. (b) Fetus on day 15 of pregnancy resulting from a zygote cultured to the blastocyst stage in modified mouse tubal fluid medium supplemented with $300 \mu$ mol ammonium $1^{-1}$ before transfer. The fetus exhibits an enlarged brain area, and retardation of the fore and hind limbs is evident.

$(P<0.05)$ and the number of fetuses $(P<0.05)$ compared with embryos cultured with all 20 amino acids in the same drop of medium for the entire culture period.
When the medium was renewed after $48 \mathrm{~h}$, all amino acid treatments significantly increased the number of implantation sites and the fetal mass compared with the control medium; the 
Table 3. Effect of amino acids on the viability of mouse zygotes cultured for $93 \mathrm{~h}$ to the blastocyst stage

\begin{tabular}{|c|c|c|c|c|c|c|}
\hline Treatment & $\begin{array}{l}\text { Percentage of } \\
\text { implantation } \\
\text { sites }^{a}\end{array}$ & $\begin{array}{l}\text { Percentage of } \\
\text { fetuses per } \\
\text { transfer }\end{array}$ & $\begin{array}{l}\text { Percentage of } \\
\text { fetuses per } \\
\text { implantation site }\end{array}$ & $\begin{array}{c}\text { Fetal mass } \\
\text { (mean } \pm \text { SEM) } \\
(\mathrm{g})\end{array}$ & $\begin{array}{l}\text { Percentage of } \\
\text { exencephalic } \\
\text { fetuses }^{\mathrm{a}}\end{array}$ & $\begin{array}{l}\text { Ammonium } \\
\text { concentration } \\
\text { after } 96 \mathrm{~h}^{\mathrm{b}} \\
\left(\mu \mathrm{mol} \mathrm{l}^{-1}\right)\end{array}$ \\
\hline \multicolumn{7}{|l|}{ Medium constant during culture } \\
\hline mMTF (control) & $53(35)$ & $26(17)$ & 49 & $0.2134 \pm 0.008^{\mathrm{e}}$ & $0(0)$ & 0 \\
\hline mMTF + 20 aa & $52(34)^{\mathrm{c}}$ & $30(20)^{d}$ & 59 & $0.2160 \pm 0.010$ & $20(4)$ & 414 \\
\hline mMTF + nonessential aa + gln & $66(44)$ & $29(19)$ & 44 & $0.2151 \pm 0.007$ & $15(3)$ & 380 \\
\hline $\mathrm{mMTF}+$ essential aa - gln & $56(37)$ & $47(31)^{* *}$ & $84^{* *}$ & $0.2422 \pm 0.007^{* *}$ & $10(3)$ & 327 \\
\hline \multicolumn{7}{|c|}{ Medium renewed after $48 \mathrm{~h}$ of culture } \\
\hline mMTF (control) & $37(25)$ & $22(14)$ & 56 & $0.1774 \pm 0.008^{\mathrm{e}}$ & $0(0)$ & \\
\hline $\mathrm{mMTF}+20 \mathrm{aa}$ & $78(52)^{\dagger+c}$ & $50(33)^{\text {td }}$ & 64 & $0.2041 \pm 0.010^{\dagger}$ & $0(0)$ & \\
\hline mMTF + nonessential aa + gln & $66(44)^{++}$ & $40(26)$ & 59 & $0.2093 \pm 0.007^{+}$ & $0(0)$ & \\
\hline mMTF + essential aa - gln & $60(40)^{\dagger}$ & $49(32)^{+\dagger}$ & $80^{\dagger \dagger}$ & $0.2319 \pm 0.007^{* *}$ & $0(0)$ & \\
\hline
\end{tabular}

$n=66$ Embryos transferred per treatment.

${ }^{a}$ Numbers are indicated in parentheses.

${ }^{h}$ Gardner and Lane (1993)

${ }^{*}{ }^{+}$Significantly different from control value $(P<0.05) ;{ }^{* *}{ }^{+\dagger}$ significantly different from control value $(P<0.01) ;{ }^{c, d}$ like pairs are significantly different from each other $(P<0.05)$; ${ }^{e}$ like pairs are significantly different $(P<0.01)$.

largest fetuses were from zygotes that had been cultured in the essential amino acids without glutamine treatment (Table 3). However, only essential amino acids without glutamine significantly increased the number of implantation sites that resulted in fetuses $(P<0.01)$. Culture in the presence of a build-up of ammonium, where the medium was not renewed, again resulted in the development of exencephaly in a percentage of fetuses, while renewal of the culture medium to alleviate the build-up of ammonium prevented the development of exencephaly (Table 3).

Effect of the duration of exposure to ammonium in culture medium on subsequent embryo viability

As there was an apparent relationship between the incidence of exencephaly and the duration of exposure to ammonium in the culture medium (Tables 1,2 and 3), the effect of exposure to $300 \mu \mathrm{mol}$ ammonium $\mathrm{I}^{-1}$ on embryo development after transfer was assessed. Embryos cultured in mMTF and transferred at either the 6-8-cell, morulae or blastocyst stage resulted in an implantation rate of 27,38 and $45 \%$, respectively. Zygotes cultured for $48 \mathrm{~h}$ in the presence of ammonium developed to morphologically normal 6-8-cell embryos at the time of transfer. However, none of the embryos transferred to recipients was viable, and no implantation sites were recorded. Transfer at the 6-8-cell stage was to synchronized recipients. In contrast, morulae and blastocysts resulting from culture with ammonium were transferred to asynchronous recipients and were able to implant at rates not significantly different from the respective controls (Table 4); ammonium in the culture medium did not affect fetal development or fetal mass of these two groups. However, there was a significant linear relationship between the duration of exposure to ammonium and the number of fetuses exhibiting exencephaly from 48 to $93 \mathrm{~h}$ $(P<0.05)$.

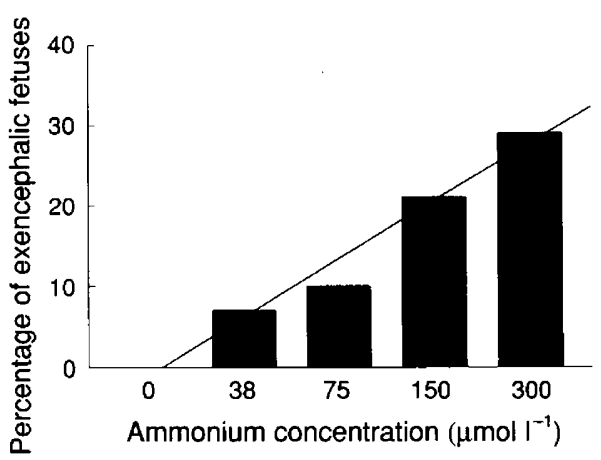

Fig. 2. Effect of ammonium concentration in culture medium on the development of exencephaly in the resultant mouse fetuses after transfer of blastocysts to recipient females. Values are expressed as the percentage of affected fetuses of all the fetuses obtained $(r=0.963$; $P<0.05)$.

\section{Effect of titration of ammonium in culture medium on embryo viability}

Culturing embryos in the presence of ammonium significantly reduced the number of implantation sites compared with culture in the absence of ammonium $(P<0.05$; Table 5). Furthermore, there was a linear relationship between ammonium concentration and the incidence of exencephaly $(P<0.05$; Fig. 2).

\section{Morphological ageing of fetuses}

The morphological ages of the fetuses generated from culture with ammonium were assessed (Table 5) and compared with fetuses resulting from the transfer of blastocysts derived in vivo (Table 6). The external features, skin, limb, eye and ear, of fetuses developed in the presence of ammonium were 


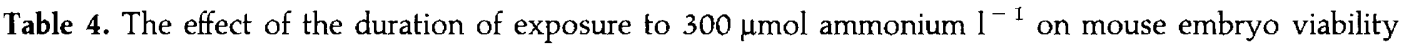

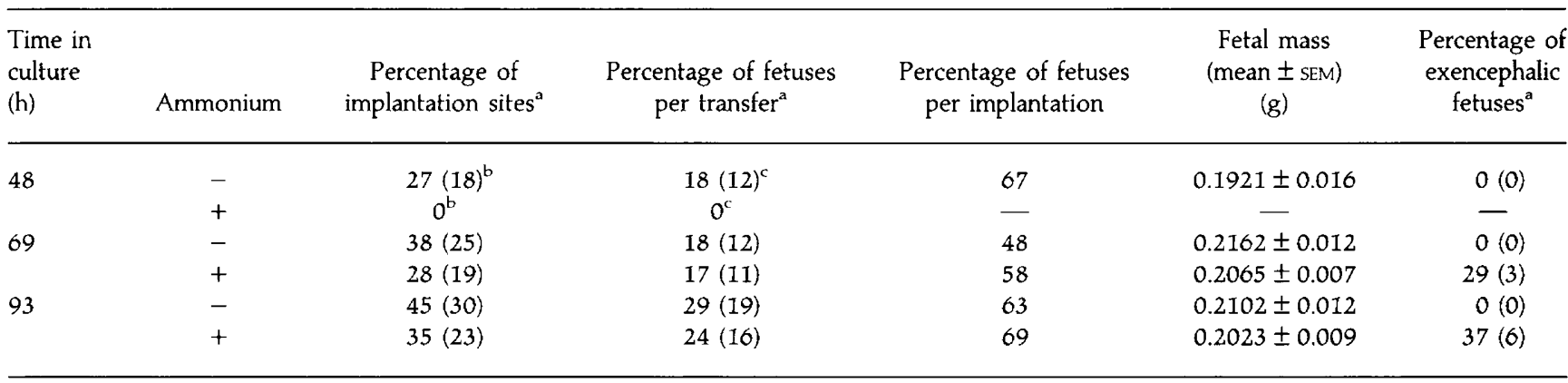

$n=66$ Embryos transferred per treatment per time point.

${ }^{a}$ Numbers are indicated in parentheses.

${ }^{b c}$ Like pairs are significantly different from each other $(P<0.05)$

From 48 to $93 \mathrm{~h}$ there was a significant linear increase in the percentage of exencephalic fetuses from embryos cultured in the presence of $300 \mu m o l$ ammonium $1^{-1}(P<0.05)$.

Table 5. The effect of ammonium concentration on subsequent mouse embryo viability after $93 \mathrm{~h}$ of culture

\begin{tabular}{|c|c|c|c|c|c|c|c|}
\hline $\begin{array}{l}\text { Ammonium } \\
\text { concentration } \\
\left(\mu \mathrm{mol} \mathrm{l}^{-i}\right)\end{array}$ & $\begin{array}{l}\text { Percentage of } \\
\text { implantation } \\
\text { sites }^{a}\end{array}$ & $\begin{array}{l}\text { Percentage of } \\
\text { fetuses per } \\
\text { transfer }^{\mathbf{a}}\end{array}$ & $\begin{array}{l}\text { Percentage of } \\
\text { fetuses per } \\
\text { implantation site }\end{array}$ & $\begin{array}{c}\text { Fetal mass } \\
\text { (mean } \pm \text { SEM) } \\
(\mathrm{g})\end{array}$ & $\begin{array}{c}\text { Estimated } \\
\text { morphological age } \\
\text { (days } \pm \text { SEM) }\end{array}$ & $\begin{array}{c}\text { Crown-rump } \\
\text { length } \\
\text { (mm } \pm \text { SEM) }\end{array}$ & $\begin{array}{l}\text { Estimated age based on } \\
\text { crown-rump length } \\
\text { (days } \pm \text { SEM })\end{array}$ \\
\hline$O$ (control) & $52(34)$ & $25(17)$ & 50 & $0.2019 \pm 0.012$ & $15.0 \pm 0.04$ & $13.8 \pm 0.3$ & $14.9 \pm 0.3$ \\
\hline 37.5 & $36(24)^{\dagger}$ & $23(15)$ & 63 & $0.2370 \pm 0.016$ & $14.9 \pm 0.02$ & $13.9 \pm 0.2$ & $14.9 \pm 0.3$ \\
\hline 75 & $25(17)^{\dagger}$ & $15(10)$ & 59 & $0.2528 \pm 0.008$ & $14.8 \pm 0.03$ & $13.6 \pm 0.4$ & $14.7 \pm 0.4$ \\
\hline
\end{tabular}

$n=66$ Embryos transferred per treatment.

${ }^{a}$ Numbers are indicated in parentheses.

based on morphology of skin, limb, eye and ear (see Table 6).

${ }^{\dagger}$ Implantation is significantly reduced by ammonium in the culture medium $(P<0.05)$

* Significantly different from control value $(P<0.05)$; ** significantly different from control value $(P<0.01)$.

assigned a developmental age based on fetuses derived in vivo. The values were averaged to give an estimated morphological age for each fetus. Fetal development as assessed by morphology was significantly retarded by half a day when embryos were cultured in medium with an ammonium concentration of $150 \mu \mathrm{mol} \mathrm{l}^{-1}(P<0.05)$. Increasing the ammonium concentration in the medium to $300 \mu \mathrm{mol} \mathrm{l}^{-1}$ retarded fetal development by 0.8 of a day $(P<0.01)$. Culturing embryos in the presence of ammonium also significantly reduced crown-rump length at a concentration of $150 \mu \mathrm{mol} \mathrm{l}^{-1}(P<0.05)$. Increasing the ammonium concentration to $300 \mu \mathrm{mol} \mathrm{l^{-1 }}$ further reduced crown-rump length $(P<0.01)$ compared with the control length. The crown-rump length for fetuses that developed in the presence of ammonium was compared with that of fetuses derived in vivo as a second method of ageing the fetuses, and confirmed that ammonium significantly retards fetal growth at concentrations of $150 \mu \mathrm{mol} \mathrm{l}^{-1}(P<0.05)$ and $300 \mu \mathrm{mol} \mathrm{l}^{-1}(P<0.01)$.

\section{Discussion}

The main findings of this study are that amino acids increase the postimplantation development of mouse embryos cultured in vitro, the beneficial effects of amino acids (when the culture period is greater than $48 \mathrm{~h}$ ) are dependent upon the alleviation of ammonium toxicity resulting from the metabolism and breakdown of amino acids in the medium, and that the presence of ammonium in the culture medium reduces implantation, retards subsequent fetal development and induces exencephaly in a dose-dependent manner.

Eagle's nonessential amino acids and glutamine have been shown to stimulate cleavage, blastocyst formation and subsequent hatching of mouse zygotes in vitro. Consistent with their observed benefits conferred in vitro, nonessential amino acids and glutamine significantly increased the implantation rate and subsequent fetal development after $48 \mathrm{~h}$ of culture. Unlike the nonessential amino acids and glutamine, essential amino acids without glutamine significantly decrease the number of cells in blastocysts in culture (Gardner and Lane, 1993). However, in contrast to their effects in vitro, essential amino acids without glutamine had no adverse effect on implantation or fetal development after $48 \mathrm{~h}$ of culture. Previously, it has been demonstrated that mouse zygotes cultured to the four-cell stage with all 20 Eagle's amino acids and a chelating agent EDTA increases subsequent viability (Mehta and Kiessling, 1990). In contrast, this study demonstrated that 
Table 6. Morphological time scale of fetal development for mouse $F_{1}$ blastocysts derived in vivo

\begin{tabular}{|c|c|c|c|c|c|c|}
\hline $\begin{array}{l}\text { Day of } \\
\text { pregnancy }\end{array}$ & $\begin{array}{c}\text { Skin } \\
\text { features }\end{array}$ & $\begin{array}{l}\text { Limb } \\
\text { features }\end{array}$ & $\begin{array}{c}\text { Eye } \\
\text { features }\end{array}$ & $\begin{array}{c}\text { Ear } \\
\text { features }\end{array}$ & $\begin{array}{l}\text { Crown-rump } \\
\text { length } \\
\text { (mm } \pm \mathrm{seM})\end{array}$ & $\begin{array}{c}\text { Fetal mass } \\
(\mathrm{g} \pm \mathrm{SEM})\end{array}$ \\
\hline 13 & Large head follicles & $\begin{array}{l}\text { F footplates } \\
\mathrm{H} \text { smooth }\end{array}$ & $\begin{array}{l}\text { Round } \\
\text { Cornea barely evident } \\
\text { Very fine ring of pigment }\end{array}$ & $\begin{array}{l}\text { Distinct meatus } \\
\text { and pinna } \\
\text { protrusion }\end{array}$ & $9.1 \pm 0.3$ & $0.1436 \pm 0.007$ \\
\hline 14 & $\begin{array}{l}\text { Follices on } \\
\text { central abdomen }\end{array}$ & $\begin{array}{l}\text { F separated digits } \\
\mathrm{H} \text { webbed digits }\end{array}$ & $\begin{array}{l}\text { Round } \\
\text { Faint cornea } \\
\text { Circle of pigment }\end{array}$ & $\begin{array}{l}\text { Pinna growing out } \\
\text { and forward }\end{array}$ & $11.3 \pm 0.2$ & $0.1786 \pm 0.005$ \\
\hline 15 & $\begin{array}{l}\text { Foilicles on the } \\
\text { head and abdomen }\end{array}$ & $\begin{array}{l}\text { F splayed digits } \\
\mathrm{H} \text { separated and } \\
\text { beginning to splay }\end{array}$ & $\begin{array}{l}\text { Beginning to elongate } \\
\text { Distinct cornea } \\
\text { Dark pigment }\end{array}$ & $\begin{array}{l}\text { Distinct pinna flap } \\
\text { almost over } \\
\text { meatus }\end{array}$ & $14.1 \pm 0.2$ & $0.3255 \pm 0.009$ \\
\hline
\end{tabular}

F: forelimb; H: hind limbs.

only nonessential amino acids and glutamine enhanced the implantation rate of embryos at the cleavage stage. However, EDTA was not in the media used in these experiments.

Similar to data obtained after culture for $48 \mathrm{~h}$, the highest implantation rate for embryos cultured for $69 \mathrm{~h}$ occurred after culture with nonessential amino acids and glutamine, and fetal development per transfer was increased in all amino acid treatments. Significantly, the number of fetuses per implantation site and fetal mass were increased only by essential amino acids without glutamine.

When preimplantation mouse embryos were cultured in the same drop of medium for a further $24 \mathrm{~h}$ ( $93 \mathrm{~h}$ in total), amino acids no longer had an effect on the implantation rate after transfer. However, the observed loss of stimulation of postimplantation development can be attributed to the significant concentration of ammonium (about $400 \mu \mathrm{mol} \mathrm{l^{-1 }}$ ) present in the medium at this time (Gardner and Lane, 1993). The contention that ammonium impairs subsequent postimplantation development is consistent with its reported detrimental effects during the preimplantation period. Exposure to ammonium in culture decreases mouse embryo cleavage and blastocyst development (Gardner and Lane, 1993), impairs the development of sheep embryos through the 8-16-cell stage (Gardner et al., 1994), and significantly reduces blastocyst development and number of cells in cattle embryos generated by IVM and IVF (D.K. Gardner and L.J. Maclellan, unpublished). After culture for $93 \mathrm{~h}$, during which the medium was renewed to alleviate ammonium toxicity, implantation was increased by all amino acid treatments, although only the essential amino acids without glutamine increased fetal development per implantation. The increase of the implantation rate and fetal development by essential amino acids without glutamine was reported for eight-cell rat embryos cultured to the blastocyst stage (Zhang and Armstrong, 1990). The data obtained are consistent with the theory that essential amino acids without glutamine stimulate the development of the inner cell mass, which is reflected as an increase in fetal development.

The observed changes in amino acid requirements during the preimplantation period are consistent with the changing physiology of the embryo as development proceeds. The transition from zygote to blastocyst is not only associated with several morphological events, such as compaction and blastocoel formation, but also with major changes in energy metabolism. The changing energy metabolism of the embryo is reflected by changes in nutrient requirements (Biggers et al., 1989). Alternatively, the initial preference for nonessential amino acids by embryos at the cleavage stage and the switch to all 20 amino acids being preferred at the blastocyst stage may reflect the activation of transport systems for these amino acids at different stages of development. It is known that the uptake of the amino acids methionine (essential) (Kaye et al., 1982), glycine (nonessential) (Hobbs and Kaye, 1985, 1986), alanine (nonessential) and lysine (essential) (Van Winkle, 1988) increase, and that proline (nonessential) transport decreases throughout development (Van Winkle, 1988). Unfortunately, little is known about the interactions between amino acids for transport systems. However, it has been shown that cysteine (essential) and glutamate (nonessential) do compete for a $\mathrm{Na}^{+}$-independent transport system in the mouse zygote and two-cell embryo (Van Winkle et al., 1992).

Compared with culturing embryos singly, culturing mammalian embryos in groups or in reduced volumes increases blastocyst formation and number of cells (Wiley et al., 1986; Paria and Dey, 1990; Lane and Gardner, 1992; Gardner et al., 1994), and increases the viability of mouse embryos (Lane and Gardner, 1992). However, culture with amino acids requires that the medium be renewed every $48 \mathrm{~h}$ to alleviate the build-up of embryo-toxic ammonium, thereby removing any embryo-derived factor(s) and compromising subsequent embryo development. To resolve this problem we developed an enzymatic method to transaminate ammonium to glutamate in the culture medium, eliminating the need to move the embryos to fresh medium. Data indicate that development in vitro (Lane and Gardner, 1993) and in vivo (M. Lane and D.K. Gardner, unpublished) is increased by this method of ammonium removal, which allows continual exposure of embryos to any autocrine or paracrine factor(s).

The development of exencephaly in fetuses after transfer was not evident until they had been cultured in the presence of amino acids for $69 \mathrm{~h}$. By this time, up to $400 \mu \mathrm{mol}$ ammonium $1^{-1}$ has been generated (Gardner and Lane, 1993). The development of exencephaly depended upon the concentration 
of ammonium in a medium free of amino acids. Although ammonium significantly reduced the implantation rate, it had no effect on numbers of fetuses and fetal mass. However, ammonium significantly retarded fetal development, as assessed by morphology, in a dose-dependent manner. Consistent with this data, Goldman and Vokovac (1964) showed that ammonium chloride retards fetal growth when administered to pregnant mice. It has been reported that exposure of the preimplantation mouse embryo to various agents in vitro can result in fetal abnormalities after transfer to recipients. For example, exposure of mouse blastocysts to methyl nitrosourea before transfer results in a reduction in live birth rate and an increase in neonate mortality rate (Iannoccone, 1984), while the direct administration of methyl nitrosourea to pregnant female mice during the preimplantation phase induces exencephaly, cleft palate and tail abnormalities in resultant fetuses (Takeuchi, 1984). Some vitrification solutions have also been shown to induce fetal malformations in mice when used to cryopreserve oocytes (Kola et al., 1988). The mechanism of action of such agents remains largely unknown (Kimmel et al., 1993).

In conclusion, we demonstrated that the preimplantation mouse embryo appears to undergo a change in nitrogen requirements as development proceeds; the different groups of amino acids have different effects on postimplantation development: the nonessential amino acids and glutamine increase the implantation rate while the essential amino acids enhance fetal development. Furthermore, we have shown that allowing ammonium to build up in the culture medium results in reduced implantation, retarded fetal growth and development of exencephaly in a dose-dependent manner.

We thank Professor B. Bavister for critical comments on the manuscript, and Dr P. McLoud for assistance with the linear-logistic regression. This work was supported by a grant awarded to D. K. Gardner by Monash IVF Ltd. D. K. Gardner was supported by a Fellowship from the Australian Research Council; M. Lane was supported by a Studentship from the Australian NH and MRC.

\section{References}

Baker RJ (1988) Glim 3.77 Reference Guide. Numerical Algorithims Group, Oxford

Bavister BD (1987) Studies on the developmental blocks in cultured hamster embryos. In The Mammalian Preimplantation Embryo pp 219-249 Ed. BD Bavister. Plenum Press, New York

Bavister BD and McKiernan SH (1993) Regulation of hamster embryo development in vitro by amino acids In Preimplantation Embryo Development pp 57-72 Ed. BD Bavister. Plenum Press, New York

Biggers JD, Gardner DK and Leese H) (1989) Control of carbohydrate metabolism in preimplantation embryos. In Growth Factors in Mammalian Development pp 19-32 Eds IY Rosenblum and S Heyner. CRC Press, Boca Raton

Bowman P and McLaren A (1970a) Cleavage rate of mouse embryos in vivo and in vitro Journal of Embryology and Experimental Morphology 24 203-207

Bowman P and McLaren A (1970b) Viability and growth of mouse embryos after in vivo culture and fusion Journal of Embryology and Experimental Morphology 23 693-704

Chatot CL, Ziomek CA, Bavister BD, Lewis JL and Torres I (1989) An improved culture medium supports development of random-bred 1-cell mouse embryos in vitro Journal of Reproduction and Fertility 86 679-688

Eagle H (1959) Amino acid metabolism in mammalian cell cultures Science 130 $432-437$
Fahning ML, Schultz RH and Graham EF (1967) The free amino acid content of uterine fluids and blood serum in the cow Journal of Reproduction and Fertility $13229-236$

Gardner DK and Lane $\mathbf{M}$ (1993) Amino acids and ammonium regulate the development of preimplantation mouse embryos in culture Biology of Reproduction 48 377-385

Gardner DK, Lane M, Spitzer A and Batt PA (1994) Enhanced rates of cleavage for sheep zygotes cultured to the blastocyst stage in vitro in the absence of serum and somatic cells: amino acids, vitamins and culturing embryos in groups stimulate development Biology of Reproduction 50 390-400

Goddard MJ and Pratt HPM (1983) Control of events during early cleavage of the mouse embryo: an analysis of the '2-cell block' Journal of Embryology and Experimental Morphology 73 111-133

Goldman AS and Vokovac WC (1964) Salicylate intoxication and congenital anomalies Archives of Environmental Health 8648656

Harlow GM and Quinn P (1982) Development of preimplantation mouse embryos in vivo and in vitro Australian Journal of Biological Science 35 $187-193$

Hobbs JG and Kaye PL (1985) Glycine transport in mouse eggs and preimplantation embryos Journal of Reproduction and Fertility 74 77-86

Hobbs JG and Kaye PL (1986) Glycine and $\mathrm{Na}^{+}$transport in preimplantation mouse embryos Journal of Reproduction and Fertility 77 61-66

Iannaccone PM (1984) Long term effects of exposure to methyl nitrosourea on blastocysts following transfer to surrogate female mice Cancer Research $\mathbf{4 4}$ 2785-2789

Kaye PL, Schultz GA, Johnson MH, Pratt HPM and Church RB (1982) Amino acid transport and exchange in preimplantation mouse embryos Journal of Reproduction and Fertility $65367-380$

Kimmel CA, Generoso WM, Thomas RD and Bakshi KS (1993) A new frontier in understanding the mechanisms of developmental abnormalities Toxicology and Applied Pharmacology 119 159-165

Kola I, Kirby C, Shaw J, Davey A and Trounson A (1988) Vitrification of mouse oocytes results in aneuploid zygotes and malformed fetuses Teratology $\mathbf{3 8}$ $467-474$

Lane M and Gardner DK (1992) Effect of incubation volume and embryo density on the development and viability of mouse embryos in vitro Human Reproduction 7 558-562

Lane M and Gardner DK (1993) In situ removal of embryo-toxic ammonium ions generated by the metabolism and breakdown of amino acids in culture media Proceedings of the 24th Annual Meeting of the Australian Society for Reproductive Biology 32 (Abstract)

Lane M and Gardner DK (1994) Amino acids increase mouse embryo viability Theriogenology 41233 (Abstract)

Mehta TS and Kiessling AA (1990) Development potential of mouse embryos conceived in vitro and cultured in ethylenediaminetetraacetic acid with or without amino acids or serum Biology of Reproduction 43 600-606

Miller JGO and Schultz GA (1987) Amino acid content of preimplantation rabbit embryos and fluids of the female reproductive tract Biology of Reproduction 36 125-129

Paria BC and Dey SK (1990) Preimplantation embryo development in vitro: cooperative interactions among embryos and role of growth factors Proceedings of the National Academy of Sciences USA 87 4756-4760

Schultz GA, Kaye PL, McKay DJ and Johnson MH (1981) Endogenous amino acids pool sizes in mouse eggs and preimplantation embryos Journal of Reproduction and Fertility $61387-393$

Takeuchi IK (1984) Teratogenic effects of methylnitrosourea on pregnant mice before implantation Experientia 40 879-881

Van Winkle LJ (1988) Amino acid transport in developing animal oocytes and early conceptuses Biochimica et Biophysica Acta 947 173-208

Van Winkle LJ, Mann DF, Wasserlauf HG and Patel M (1992) Mediated $\mathrm{Na}^{+}$-independent transport of L-glutamate and L-cystine in 1- and 2-cell mouse conceptuses Biochimica et Biophysica Acta 1107 299-304

Wahlsten D and Wainwright P (1977) Application of a morphological time scale to hereditary differences in prenatal mouse development Journal of Embryology and Experimental Morphology 42 79-92

Wiley LM, Yamami S and Van Muyden D (1986) Effect of potassium concentration, type of protein supplement, and embryo density on mouse preimplantation development in vitro Fertility and Sterility 45 111-119

Zhang X and Armstrong DT (1990) Presence of amino acids and insulin in a chemically defined medium improves development of 8-cell rat embryos in vitro and subsequent implantation in vivo Biology of Reproduction $\mathbf{4 2}$ $662-668$ 